\title{
A new technology for removing nitrogen and phosphorus in saline wastewater by double membrane bioreactor
}

\author{
Xie Kang ${ }^{1, a}$, Song Jing ${ }^{2, b}$, Qiu Liping ${ }^{1, c}$, Wang Jiabin ${ }^{1, d}$, Zhang Shoubin ${ }^{1, e}$ Kang \\ Xingsheng ${ }^{3, f}$ and Zhang Liqing ${ }^{1, g}$
}

${ }^{1}$ School of Civil Engineering and Architecture, University of Jinan, Jinan, Shandong 250022, China

${ }^{2}$ Shandong Province Environmental Protection Technology Service Center, Jinan, Shandong 250102, China

\author{
${ }^{3}$ Shandong Academy of Environmental Science, Jinan, Shandong 250013, China \\ acea_xiek@ujn.edu.cn, bamay8369@163.com, ccea_qiulp@ujn.edu.cn, dcea_wangjb@ujn.edu.cn, \\ ecea_zhangsb@ujn.edu.cn, xingshengkang@163.com, ${ }^{9}$ cea_zhanglq@ujn.edu.cn
}

Keywords: double membrane bioreactor, forward osmosis, ultrafiltration, removal of nitrogen and phosphorus.

Abstract: With the rapid development of seawater usage, the nitrogen and phosphorus removal of saline domestic wastewater is becoming a key problem in coastal areas. Conventional biological nitrogen and phosphorus removal technology always limited by some inevitable contradictions. The double membrane bioreactor, combining the Crystallization phosphorus removal and biological nitrogen removal provides a new technology to purified the saline wastewater. The application of double membrane bioreactor is beneficial for saline domestic wastewater treatment.

\section{Introduction}

The economy developing and the population growing of coastal areas in China are rapid, and the supply of fresh water is becoming scarce quickly, which seriously restricts the sustainable development of the economy and society in these coastal areas. The characteristics of geographical location make coastal cities directly take advantage of seawater. In order to solve the water crisis, domestic seawater utilization has been attracted more attention, becoming the effective way to alleviate the contradiction between supply and demand of fresh water in coastal areas. The sea water usage is defined as the use of sea water for urban domestic miscellaneous water, and sea water flushing is the most widely used. In China, the seawater flushing pilot and demonstration projects has carried out in Dalian, Qingdao, Ningbo City, e.g. The Hongkong began large-scale use of seawater flushing from the last century at the end of 50s. At present, the Hongkong seawater supply network has covered about $80 \%$ of Hongkong's population, and save fresh water about 270 million cubic meters yearly. Although it has been greatly alleviated water crisis, the seawater has been introduced into the sewage, which has increased the difficulty of sewage treatment with higher salinity. This salt containing domestic sewage is always treated by simple two stage biological treatment, and then discharged into the deep sea. Generally, this treatment of nutrient elements such as nitrogen and phosphorus are not enough. Therefore, the excessive emissions of nitrogen and phosphorus, easily lead to increased content of nutrients in seawater. The algae blooms and accelerating eutrophication become normal in coastal areas, resulting in frequent red tides and green tide. This will be a serious impact on the landscape and economic development in coastal areas, and even affect the health of people. Therefore, it is particularly important to effectively improve the treatment efficiency of salt containing wastewater, especially nitrogen and phosphorus removal from nutrients.

At present, the economic and effective technology of nitrogen and phosphorus removal from domestic wastewater is still conventional biological method. The physical and chemical methods are often used as an effective supplement to biological methods because of their high cost and easy to make second pollution problems. It is always through nitrification and denitrification to convert nitrogen pollutants to nitrogen releasing from wastewater; and through phosphorus excessive 
absorption of poly-P bacteria eliminating excess sludge from wastewater to remove phosphorus. Because of the different requirements of each process, the contradiction between the processes is inevitable in the same sewage treatment process system. It is difficult to elevate the nitrogen and phosphorus removal efficiencies because of the contradiction between the longer generation time of nitrifying bacteria and shorter generation time of poly-P bacteria, and the competitive contradictions in carbon sources.

In recent years, the sewage discharge standards have been gradually more rigorous, leading the traditional biological nitrogen and phosphorus removal process is difficult to meet the requirements especially for salt domestic sewage discharge in coastal areas. The new nitrogen and phosphorus removal process such as nitrification and denitrifying phosphorus removal, denitrification and anaerobic ammonium oxidation, aerobic denitrification technology, can significantly improve the efficiency of nitrogen and phosphorus removal process, but these conditions are complex and are still not mature.

In this study, we try to find a new method to improve the efficiency of nitrogen and phosphorus removal from saline wastewater.

\section{Experimental design}

Phosphorus crisis makes phosphorus recovery becoming a hot research topic, and also provides a new idea for nitrogen and phosphorus removal in wastewater treatment[1]. The phosphorus recovery process with economic efficiency is mostly used in high phosphorus containing wastewater, such as aquaculture wastewater, waste leachate, sludge anaerobic digestion liquid and so on. The content of phosphorus in domestic sewage is usually less than $10 \mathrm{mg} / \mathrm{L}$, which is difficult to recove directly[2]. But the discharge of domestic sewage is huge and it has high phosphorus recovery potential. Evenmore, the municipal wastewater produced by flushing seawater is rich in calcium and magnesium ions. It creates conditions for the recovery of phosphorus crystals in sewage[3].

Therefore, it is possible to concentrate the domestic sewage generated by flushing sea water and make the enriched phosphorus combine with the calcium and magnesium ions in the sewage to crystallize. It could be no longer relied on biological phosphorus release process and avoid the contradiction between the biological nitrogen and phosphorus removal. By strengthening the nitrogen removal ability of biological system, the removal efficiency of nitrogen and phosphorus can be effectively enhanced by combining phosphate removal by crystallization with biological nitrogen removal.

Membrane separation technology can concentrate the phosphorus in domestic wastewater, while pressure driven membrane such as reverse osmosis (RO) and nanofiltration (NF) can achieve the above purpose, but the cost is higher and the operation is difficult. In recent years, the forward osmosis membrane bioreactor (OMBR) has attracted more and more attention because of its low membrane fouling and high retention capacity. In order to avoid the accumulation of salt concentration problems in forward osmosis membrane interception system, ultrafiltration or microfiltration membrane is often placed in OMBR to discharge the high concentration of ions, forming a double membrane bioreactor operation, which can elvate the operation stablity of the OMBR system[4]. The double membrane bioreactor is shown in Fig. 1.

This operation mode of the double membrane bioreactor provides a new idea for separating and concentrating the saline domestic sewage and effectively removing the phosphorus by crystallization. Some scholars have made a preliminary attempt. Luo et. al. used OMBR coupling reverse osmosis to treat municipal wastewater, and the microfiltration operated intermittently in OMBR. It can effectively control the concentration of ions in the system and promote the stable operation of the biological system. Qiu et. al. [5]operated the microfiltration membrane and forward osmosis membrane in parallel in OMBR. The calcium, magnesium and phosphorus could be effectively concentrated by forward osmosis. These riched ions through MF filtration discharged into the 
crystallization reactor, and crystallized in crystallization reactor. The removal efficiency of phosphorus was as high as $89.9 \%-97.7 \%$.

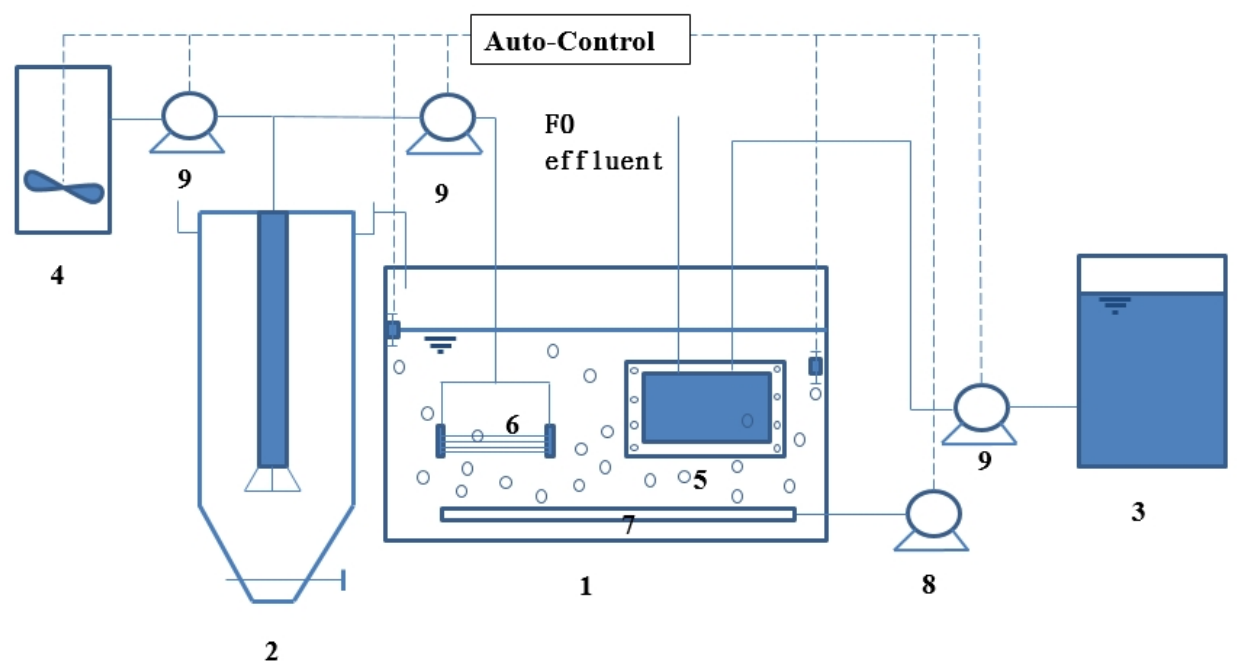

1 double membrane bioreactor ; 2 crystallization reactor ; 3 seawater draw solution ; $4 \mathrm{NaOH}$ Dosing box ; 5 membrane module of forward osmosis ; 6 membrane module of ultrafiltration ; 7 aerator ; 8

Blast aerator ; 9 peristaltic pump

Fig. 1 operation diagram of double membrane bioreactor

In order to overcome the problem of the costly regeneration of draw solution, Qiu et. al. took advantages of seawater as the draw solution. Coastal areas are rich in seawater resources and the seawater diluted by forward osmosis can be discharged directly to the sea without regeneration. It saves the cost of system operation[6].

Using seawater as the draw solution in double membrane bioreactor for treating saline sewage, it can produce the fresh water by forward osmosis membrane separation and effectively intercept the calcium, magnesium and phosphorus. When the phosphate reached saturation, it can discharge by ultrafiltration membrane filtration. After adjusted the $\mathrm{pH}$, the phosphate crystallization can be formed. It can remove phosphorus from sewage effectively without additional mineral ions, which reduced the cost of crystallization.

The phosphorus in saline sewage is removed by crystallization, resulting that the phosphorus content in the mixture is reduced. This will limit the growth of poly-P bacteria and reduce their utilization efficiency of carbon source. Thus, it can avoid the carbon source competition between the poly-P bacteria and nitrobacteria, which can improve system denitrification capability. Because of the high retention capacity of forward osmosis membrane and ultrafiltration membrane, the bacteria with longer generation time, such as ammonia oxidizing bacteria, can also be effectively enriched. This also can effectively improve the nitrification capacity of the system. Therefore, the double membrane bioreactor can solve the contradiction between nitrogen removal and phosphorus removal in the traditional biological treatment process, and effectively improve the efficiency of nitrogen and phosphorus removal[7].

The driving force of forward osmosis mainly depends on the osmotic pressure at both sides of the membrane. The concentration of sewage will lead to the decrease of the osmotic pressure at both sides of the forward osmosis membrane, which is not conducive to the removal of phosphorus by crystallization. From the operation mode of double membrane system, the operation flux of UF membrane is the key to solve this problem. How to optimize the operation mode of ultrafiltration membrane is the key to solve this problem. The influence of osmotic pressure on microbial growth and metabolism can be indirectly reflected by the effect of ion concentration on the bacterial characteristics. Therefore, it can be analyzed the bacterial characteristics such as activated sludge properties and microbial activity at different ion concentrations. It can be established the relationship 
between ion concentration and bacterial characteristics to optimize the operation parameters of double membrane bioreactor.

\section{Conclusions}

Using seawater as the draw solution of double membrane bioreactor for treating saline domestic wastewater provides a new method to remove nitrogen and phosphorus. Combining crystallization phosphorus removal and biological nitrogen removal can strengthen the system of nitrogen and phosphorus removal capacity and improve pollutant removal efficiency. A clear relationship between the system of the ion concentration and biological characteristics can effectively optimize the operation conditions of double membrane bioreactor, which can improve the efficiency and stability of the system

\section{Acknowledgements}

This work was financially supported by the research foundation of University of Jinan (XKY1618), Science and technology plan project of Shandong higher education institutions (J17KA198), National Natural Science Foundation of China (51678726, 51278225, 51408260), Science and Technology Development Projects of Shandong Province (2016GGB01157), Shandong Provincial Natural Science Foundation (ZR2013EEQ007, ZR2015EM021).

\section{References}

[1] E. Desmidt, K.Ghyselbrecht, Y.Zhang, L. Pinoy, B. Van der Bruggen, W.Verstraetee, K. Rabaeye, B. Meesschaert: critical reviews in environmental science and technology, Vol. 45(2015),p. 336

[2] P.Cornel, C.Schaum: Water Science Technology, Vol. 59(2009), p.1069

[3] Z. Yuan, , S. Pratt, , D. J. Batstone: current opinion in biotechnology, Vol. 23(2012), p. 878

[4] W.H. Luo, F.I. Hai, W.E. Price, W.S. Guo, H.H. Ngo, K. Yamamoto, L.D. Nghiem: Bioresource Technology, Vol. 200(2016), P.297

[5] G.L. Qiu, Y.M. Law, S. Das, Y.P. Ting: Environmental Science Technology, Vol. 49(2015), P.6156

[6] A. Uygur: Process Biochemistry, Vol. 41 (2006) P.61

[7] G.D. Bella, D.D. Trapani, M. Torregrossa, G. Viviani: Bioresource Technology, Vol.147(2013),P. 614 